\title{
Studi Kasus: Asuhan Kebidanan Pada Ibu Hamil Trimester III Dengan Menggunakan Kartu Skor Poedji Rochjati
}

\author{
Nur Fadjri Nilakesuma ${ }^{1 *}$, Dewi Susilawati ${ }^{2}$ Kiki Safitri $^{3}$ \\ 1,2,3 STIKes MERCUBAKTIJAYA Padang, Jalan Jamal Jamil Pondok Kopi Siteba, Padang, 25173, Indonesia
}

\begin{tabular}{|c|c|}
\hline ARTICLE INFORMATION & A B S T RA K \\
\hline $\begin{array}{l}\text { Article Trace } \\
\text { Submission: August 05, } 2019 \\
\text { Final Revision: September 25, } 2019 \\
\text { Available online: October 26, } 2019 \\
\end{array}$ & $\begin{array}{l}\text { Asuhan kebidanan berkelanjutan bertujuan untuk memberikan } \\
\text { pendampinganyang berkualitas pada ibu sepanjang masa kehamilan } \\
\text { persalnan dan pasca persalinan.. salah satu strateginya adalah dengan } \\
\text { mendeteksi kemungkinan timbulnya komplikasi ibu dan janin. Salah }\end{array}$ \\
\hline $\begin{array}{l}\text { Kata kunci : } \\
\text { Asuhan Kebidanan ; risiko rendah }\end{array}$ & $\begin{array}{l}\text { Rochjati untuk melakukan risiko yang mungkin terjadi pada ibu.. Tujuan } \\
\text { penelitian adalah mengetahui proses asuhan kebidanan dengan } \\
\text { menggunakan instrumen penapisan skor poedji Rohjati . Penelitian }\end{array}$ \\
\hline $\begin{array}{l}\text { Key Word: } \\
\text { pregnancy, Proedji Rochjati Score }\end{array}$ & $\begin{array}{l}\text { merupakan penelitian deskriptif dengan rancangan studi kasus.. Data } \\
\text { dikumpulkan melalui wawancara, observasi, pemeriksaan fisik dan } \\
\text { pemeriksaan penunjang. Jumlah responden berjumlah } 1 \text { orang dengan } \\
\text { usia kehamila trimester III. Alat yang digunakan meliputi format } \\
\text { pengkajian, kartu skor pudji rochyati, set antenatal, dan buku KIA yang } \\
\text { digunakan untuk konseling. Selama interaksi dilakukan, Responden } \\
\text { mengalami ketidaknyamanan fisiologis yang serig dialami ibu hamil } \\
\text { trimester III dan hasil penapisan risiko menunjukkan responden berada } \\
\text { pada kategori risiko rendah, }\end{array}$ \\
\hline
\end{tabular}

\section{A B S T R A C T}

The continuing midwifery care aims to provide quality in the mothers throughout the pregnancy and post-childbirth. One of his strategies is to detect possible onset of maternal and fetal complications. One of the tools that can be used is the use of Rochjati Poedji scorers to do the risk that may happen to the mother.. The purpose of research is to know the process of obstetrics and gynaecology by using the transmission of Rohjati score filtering instrument. Research is a descriptive study with the draft case study.. Data is collected through interviews, observations, physical examinations and support checks. The number of respondents was 1 with a THIRD trimester of pregnancy. The tools used include the assessment format, Pudji Rochyati scorers, antenatal sets, and the KIA books used for counseling. As long as the interaction is conducted, respondents experience physiological discomfort that is common with the III-trimester pregnant women and the risk filtering result indicates that the respondent is in a low risk category. 


\section{PENDAHULUAN}

Angka Kematian Ibu (AKI) merupakan jumlah kematian ibu selama masa kehamilan, persalinan dan nifas yang disebabkan oleh berbagai banyak faktor atau pengelolaannya tetapi bukan karena sebab-sebab lain seperti kecelakaan, terjatuh, dan lain-lain, di setiap 100.000 kelahiran hidup (Hasnita, 2018).

Di Sumatra Barat ditemukan sebanyak 16 kasus angka kematian ibu, jumlah ini mengalami penurunan jika dibanding tahun sebelumnya (20 orang). Adapun rincian kematian ibu ini terdiri dari kematian ibu hamil 4 orang, kematian ibu bersalin 4 orang dan kematian ibu nifas 8 orang. Sementara jika dilihat berdasarkan umur, kematian ibu kurang dari 20 tahun (Tidak beresiko) sebanyak 1 orang, umur 34 tahun (Beresiko) sebanyak 8 orang dan diatas 35 tahun sebanyak 7 orang (DKK, 2017).

Angka kematian ibu dan bayi disebabkan oleh Beberapa factor yaitu faktor 3 terlambat : terlambat mengambil keputusan saat rujukan dapat menimbulkan keterlambatan untuk sampai ditempat rujukan dan terlambat mendapatkan pertolongan. Salah satu cara untuk mengurangi keterlambatan tersebut adalah dengan identifikasi faktor resiko. Tindakan identifikasi faktor resiko ini dapat dilakukan bidan mulai dari kontrak pertama ibu hamil dengan menggunakan Kartu Skor Poedji Rochyati. Tindakan ini didapatkan oleh ibu hamil saat melakukan kunjungan kehamilan. Karena tujuan kunjungan ini adalah menjaga agar ibu hamil dapat melalui masa kehamilan, persalinan dan nifas dengan baik dan selamat, serta menghasilkan bayi yang sehat tanpa adanya penyulit, kelainan dan komplikasi (Danur, 2018).

Komplikasi kehamilan yang tidak terdeteksi secara dini akan berlanjut menjadi komplikasi yang serius yang akan mengancam jiwa ibu maupun janin sehingga meningkatkan angka kesakitan dan kematian ibu maupun janin. Bidan sebagai petugas kesehatan terdepan yang paling banyak berhubungan dengan ibu hamil dalam memberikan perawatan kehamilan (antenatal care) diharapkan meningkatkan cakupan skrining faktor risiko dengan menggunakan teknologi sederhana dan mudah yaitu Kartu Skor Pudji Rocjati (KSPR), memberikan pelayanan antenatal yang berkualitas sesuai dengan kondisi dan faktor risiko kehamilan (Ummah, 2015).
Skor "Poedji Rochjati" merupakan salah satu upaya dalam melakukan deteksi dini risiko tinggi ibu hamil oleh tenaga kesehatan yang bertujuan mendeteksi secara awal kondisi/ status kehamilan seorang ibu apakah masuk pada kelompok ibu tidak berisiko atau berisiko. Nilai dan skor yang tertulis dalam model rujukan dapat mengklasifikasikan rujukan pada ibu hamil dengan risiko berdasarkan kelompok risiko. Skor awal ibu hamil adalah 2. (Rochjati, 2003).

Kartu skor Pordji Rochjati menggambarkan masalah atau faktor resiko pada ibu hamil dan dikelompokkan menjadi 3, yaitu kelompok ada potensi gawat darurat (APGO) yang berarti ada masalah yang perlu diwaspadai, Ada Gawat Obstetrik (AGO) yaitu ada tanda bahaya awal dan Ada Gawat Darurat Obstetri (AGDO) yang mengancam nyawa ibu dan bayi (Rochjati, 2003).

Jika tindakan tersebut dilaksanakan dengan baik, diharapkan dapat mengurangi angka kematian ibu dari faktor 3T sehingga keterlambatan dalam rujukan dan mendapatkan pertolongan di tempat rujukan dapat dihindari (Nilakesuma and Machmud, 2018). Tujuan penelitian ini adalah memberikan asuhan kebidanan dengan menggunakan kartu skor poedji rochjati.

\section{METODE PENELITIAN}

Jenis penelitian merupakan penelitian deskriptif dengan rancangan pelaksanaan asuhan pada studi kasus bersifat eksplanatori. Asuhan kebidanan dilaksanakan April-Mei disalah satu bidan praktik mandiri di Pasaman Sumatra Barat. Data dikumpulkan melalui wawancara, observasi, pemeriksaan fisik seorang ibu hamil trimester 3. Alat yang digunakan meliputi format pengkajian, kartu skor pudji rochyati, set antenatal, dan buku KIA yang digunakan untuk konseling.

\section{HASIL DAN PEMBAHASAN}

Ny.S berusia 26 tahun, hamil pertama kali, dan memasuki usia kehamilan trimester III. Selama kehamilan ini status imuniasi tetanus toksoid ibu adalah TT2, tidak ada riwayat penyakit hipertensi, jantung dan TBC. Ibu tidak pernah memiliki riwayat penyakit berat atau mengalami operasi sebelum menjalani kehamilan ini. 
Jumlah kontak dengan ibu adalah 2 kali kontak. Pada usia kehamilan 34 minggu dan usia kehamilan 36 minggu. Ketika kontak pertama kali, Ibu mengeluh semakin besar kehamilan, membuat bagian dada terasa sesak. Hasil pemeriksaan fisik selama beberapa kali kontak dengan ibu mendapatkan data bahwa tanda vital ibu dalam batas normal. Tinggi badan ibu adalah $155 \mathrm{~cm}$, berat bada ibu sebelum hamil 49.kg. Kenaikan berat badan selama hamil adalah 12 $\mathrm{kg}$.

Selama kontak dengan responden, perkembangan TFU sesuai dengan Tinggi fundus uterus normal menurut hukum $\mathrm{Mc}$ Donald:

\section{Rumus Mc Donald}

Gestational age $($ Bulan $)=\mathrm{TFU}(\mathrm{Cm}) / 1 \times 2 / 7$ atau $( \pm 3.5)$ Gestational age $(\mathrm{Minggu})=\mathrm{TFU}(\mathrm{Cm}) / 1 \times 8 / 7$

TFU pada kunjungan pertama dilakukan adalah $29 \mathrm{~cm}$ dan naik menjadi $30 \mathrm{~cm}$ pada saat kunjungan kedua di tanggal 13 Mei 2019. Selama kontak, gerakan janin dapat dirasakan ibu namun ibu mengalami hambatan untuk mengitung gerakan janin. Detak jantung janin dalam rentang normal antara $140-145$ kali/menit.

Hasil penapisan menggunakan SKOR POEDJI ROCHJATI menghasilkan skor 2. Hasil pengisian KSPR dapat dilihat dibawah ini

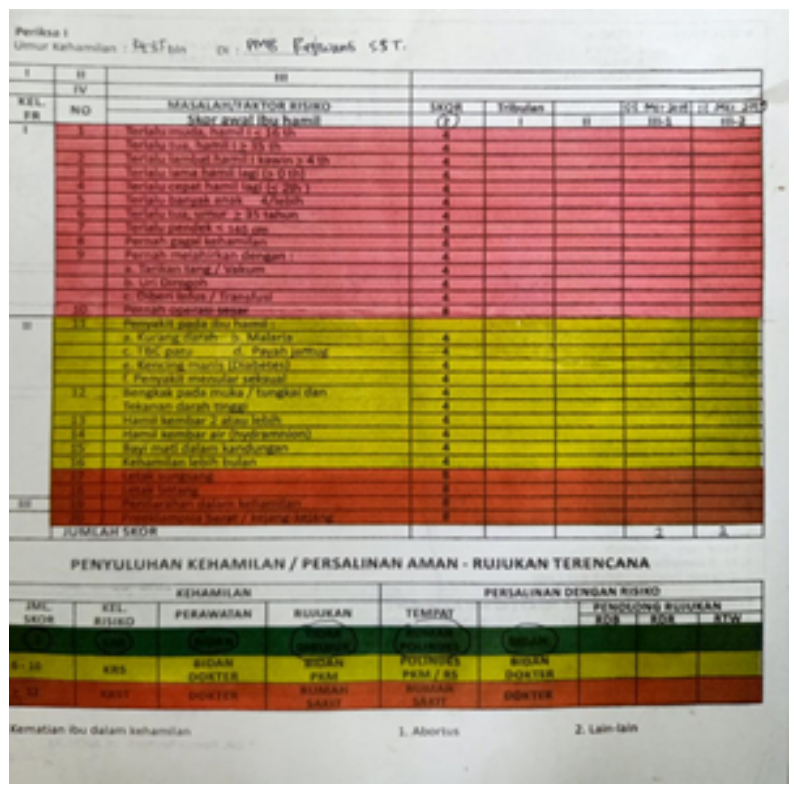

Hasil skor yang ditampilkan yang didapatkan bahwa Ny.S tidak ada deteksi resiko tinggi dan bisa melahirkan dengan normal. Asuhan yang diberikan yaitu mengajarkan cara menghilangkan rasa sesak pada bagian dada dengan cara memberitahu kepada ibu untuk tidur miring kekiri dan kekanan, menghindar hindari untuk tidak tidur dengan posisi telentang. Rencana asuhan kebidanan lain yang dilakukan adalah menganjurkan ibu untuk mengurangi konsumsi air pada malam hari dan memperbanyak minum pada siang hari

\section{PEMBAHASAN}

Selama kehamilan, ibu hamil akan mengalami ketidaknyaman. Hal ini merupakan salah satu respon tubuh terhadap kehamilan, tidak terkecuali sistim respirasi. Dyspnea adalah istilah medis untuk sesak napas atau sesak napas, dan ini merupakan gejala kehamilan yang sangat umum. Faktanya, sekitar $60-70 \%$ dari ibu yang hamil mengatakan mereka kadang-kadang merasa sesak nafas. Salah satu gejala dari dyspnea adalah sesak pada bagian dada dan lebih sulit untuk mendapatkan udara melalui tenggorokan (Get, 2019).

Sensasi sesak pada dada selama kehamilan merupakan upaya dari sistim respirasi terhadap peningkatan usia kehamilan. Hal ini disebabkan oleh posisi diafragma yang naik sekitar $5 \mathrm{~cm}$ dari keadaan sebelum hamil. Naiknya diafragma ini menyebabkan terjadinya penurunan FRC. Disamping itu, Selama kehamilan, ekspansi dinding dada digeser menuju tulang rusuk karena tekanan perut dan tulang rusuk bagian bawah. berkat meningkatnya area aposisi, tekanan perut yang ditimbulkan oleh kontraksi diafragma bekerja terutama pada bagian bawah tulang rusuk, sehingga mengangkat dan memperluas tulang rusuk di mana diafragma berada (Lomauro and Aliverti, 2015).

Pada ibu hamil disarankan untuk tidur dengan posisi miring kiri atau kanan (Sukorini, 2017). Disamping tekanan pada diafragma, ketidaknyaman yang dirasakan pasien juga disebabkna oleh semakin bertambahnya perkembangan janin dalam perut ibu, yang mengakibatkan tertekannya diafragma sehingga menyebabkan ibu merasa sesak pada bagian dada.

Ketidaknyaman lain yang dirasakna pasien adalah sering buang air kecil. Menurut (Mandan, 
2016) sering BAK merupakan hal yang fisiologis, dimana keluhan ini akan dirasakan ibu ketika memasuki trimester III dikarenakan bagian bawah janin mulai membesar menekan kandung kemih dan menambah beban berat ibu. Disamping itu, perubahan kadar hormone $\mathrm{HCG}$ membuat peningkatan terhadap kinerja ginjal menjadi berlipat ganda, sehingga pasien merasakan sering BAK (Editors, 2019) . Upaya yang diberikan kepada pasien adalah menganjurkan ibu agar banyak minum pada siang hari, mengurangi minum pada malam hari serta mengurangi konsumsi minuman yang mengandung dieuretik seperti cafeein pada kopi dan the. Asupan tinggi kafein dapat meningkatkan pengeluaran kalsium urin melalui mekanisme penurunan reabsorbsi kalsium di ginjal sehingga menyebabkan keseimbangan kalsium menjadi negatif yang nantinya akan mempengaruhi kepadatan tulang (Eva Yulia Safitri, 2015).

Pendekatan risiko merupakan salah satu cara untuk mengetahui ada tidaknya kehamilan risiko tinggi yang kemungkinan dapat menyebabkan terjadinya bahaya atau komplikasi baik terhadap ibu maupun janin yang dikandungnya selama masa kehamilan, melahirkan ataupun nifas.(Zannah, 2013).

Potensi risiko kehamilan dan persalinan kemungkinan akan berpengaruh terhadap risiko terjadinya komplikasi pada persalinan dan komplikasi atau kegawatan pada persalinan juga dapat dipengaruhi oleh derajat faktor risiko. Apabila semakin tinggi tingkatan risiko faktor risiko pada ibu hamil maka semakin tinggi juga ibu akan mengalami komplikasi. Selain itu, faktor predisposisi juga dapat mempengaruhi tingkat risiko kehamilan antara lain pengetahuan, faktor sosial ekonomi juga dapat berpengaruh pada gizi ibu hamil yaitu tentang biaya dalam perawatan kehamilan dan persalinan (Prwawirahardjo, 2010).

Hasil asuhan kebidanan pada ibu didapatkan hasil kehamilan Ny. S terkategori kehamilan dengan resiko rendah (KRR). Kategori resiko kehamilan Ny.S berpotensi menjadi kehamilan resiko tinggi hingga persalinan. Hal ini disebabkan Resiko kehamilan ini bersifat dinamis karena ibu hamil yang pada mulanya normal, secara tiba - tiba dapat beresiko tinggi. Jika status kesehatan ibu hamil buruk, misalnya menderita anemia maka bayi yang dilahirka beresiko lahir dengan berat badan rendah, bayi dengan BBLR ini memilki resiko kesakitan seperti infeksi saluran nafas bagian bawah dan kemtian yang lebih tinggi dari pada bayi yang dilahirkan dengan berat badan normal (Kusmiyati., 2008).

\section{KESIMPULAN}

Hasil penilaian factor risiko menunjukkan ibu masuk kedalam kategori risiko rendah. Hal ini sesuai dengan keluhan yang dialami ibu adalah keluhan yang masuk kedalam rentang fisiologi perubahan kehamilan trimester III

\section{DAFTAR PUSTAKA}

Danur, A. (2018). Faktor-Faktor Yang Berhubungan Dengan Peran Bidan Dalam Pemantauan Dan Deteksi Dini Resiko Tinggi Kehamilan Di Wilayah Kerja Puskesmas Basuki. Jurnal Keperawatan Silampari (JKS) Volume 2, No 1, 3.

DKK. (2017). Profil Kesehatan Kota Padang. Profil Kesehatan Kota Padang Tahun 2017, 25.

Editors, e. (2019) 'spending lots of time in the loo these days? Learn more about excessive urination during pregnancy, including how to break free of the every10-minute pee .', 4, pp. 1-7.

Eva yulia safitri, d. Y. F. (2015) 'of nutrition college, volume halaman of nutrition college, volume halaman online di: http://ejournal-s1.undip.ac.id/index.php/jnc journal of nutrition college, volume 4 , nomor 2 , tahun 2015', 4.

Get, h. (2019) 'shortness of breath and rib pain in pregnancy', pp. 1-8.

Hasnita. (2018). Hubungan Pengetahuan Ibu Hamil Dengan Keteraturan kunjungan antenatal care dipuskesmas turikale kabupaten marols. Jurnal Ilmiah Kesehatan Diagnosis Volume 12, 1 .

Kusmiyati. (2008). Perawatan Ibu Hamil. Yogyakarta: Fitra Mya.

Lomauro, a. And aliverti, a. (2015) 'respiratory physiology of pregnancy physiology masterclass', 11(4), pp. 297-301.

Mandan. (2016). Asuhan kebidanan. Bogor: In Media.

Nilakesuma, n. F. And Machmud, r. (2018) 'jurnal kedokteran dan kesehatan indonesia 
maternity references on the maternal mortality: decision-making pattern perpective', jurnak kedokteran dan kesehatan indonesia, 9(2), pp. 89-94. Doi: 10.20885/jkki.vo19.iss2.art5.

Prwawirahardjo, S. (2010). Ilmu Kebidanan . Jakarta : YBP-SP.

Rochjati, P. (2003). Skrining antenatal pada ibu hamil:pengenalan faktor risiko. Surabaya: AirlanggaUniversity Press.

Sukorini, M. U. (2017). Hubungan Gangguan Kenyamanan Fisik Dan Penyakit dengan kualitas tidur pada ibu hamil TM III. The
Indonesian Journal of Public Health, Vol. 12 No. $1,2$.

Ummah, f. (2015) 'kontribusi faktor risiko i terhadap komplikasi kehamilan di rumah sakit muhammadiyah surabaya faizatul', surya, 7(1).

Zannah, a. N. (2013) 'pendekatan resiko kehamilan kartu skor poedji rochjati (kspr) dengan pola rujukan di rsd dr. Soebandi jember', jurnal kesehatan dr. Soebandi, 2(1), pp. 99-105. 